BULLETIN Bulletin hispanique

HISPANIQUE Université Michel de Montaigne Bordeaux

115-1 | 2013

Poésie et société en Espagne : 1650-1750

\title{
Marta P. Cacho Casal, Francisco Pacheco y su «Libro de retratos»
}

Fundación Focus-Abengoa / Marcial Pons, Sevilla / Madrid, 2011

\section{Rafael Bonilla Cerezo}

\section{OpenEdition}

\section{Journals}

Edición electrónica

URL: http://journals.openedition.org/bulletinhispanique/2583

DOI: 10.4000/bulletinhispanique.2583

ISSN: 1775-3821

\section{Editor}

Presses universitaires de Bordeaux

\section{Edición impresa}

Fecha de publicación: 1 junio 2013

Paginación: 363-371

ISBN: 978-2-86781-898-1

ISSN: 0007-4640

\section{Referencia electrónica}

Rafael Bonilla Cerezo, « Marta P. Cacho Casal, Francisco Pacheco y su «Libro de retratos» », Bulletin

hispanique [En línea], 115-1 | 2013, Publicado el 07 diciembre 2013, consultado el 23 septiembre 2020.

URL : http://journals.openedition.org/bulletinhispanique/2583 ; DOI : https://doi.org/10.4000/

bulletinhispanique.2583

Este documento fue generado automáticamente el 23 septiembre 2020.

Tous droits réservés 


\title{
Marta P. Cacho Casal, Francisco Pacheco y su «Libro de retratos»
}

\author{
Fundación Focus-Abengoa / Marcial Pons, Sevilla / Madrid, 2011
}

\author{
Rafael Bonilla Cerezo
}

\section{REFERENCIA}

Marta P. Cacho Casal, Francisco Pacheco y su «Libro de retratos», Sevilla / Madrid, Fundación Focus-Abengoa / Marcial Pons, 2011, 376 pp.

1 Entre las facetas de Pacheco menos subrayadas por los historiadores del Arte se cuenta la de compilador de la poesía de Baltasar del Alcázar, quien tituló al suegro de Velázquez como «Protógenes andaluz». Y es cierto que en la Sevilla barroca este pintor gozaba de predicamento, a la altura del que mereció el gran rival de Apeles en la Grecia clásica. Guste o no, más allá de que todavía haya quien se pregunte si fue digno de una fama tan remontada, Francisco Pacheco disfrutaba de bien ganado crédito como maestro del pincel (y de otras muchas cosas). Hasta el punto de no otear a ningún «Apeles» que pusiera en entredicho su rincón de privilegio. Pronto sabría, sin embargo, de la existencia de un aprendiz que -gracias a una radiante paradoja, teñida de hadoformaba parte ya de su familia y apenas iba a tardar en destronarlo.

2 Las razones aducidas por el mismo Pacheco en el capítulo XII de la segunda parte de su Arte de la pintura («Por qué aciertan sin cuidado muchos pintores y, poniéndolo, no consiguen su intento») ayudan a explicar los repuntes y desmayos de unos nombres y otros en el mercado de los colores y la perspectiva. Siempre a tenor del gusto -otro concepto peliagudo- de críticos, mirones y visitantes. Por qué Pacheco es juzgado hoy un eslabón inicial en la trayectoria de Velázquez no se le escapa a casi nadie, pero más interés, si cabe, suscitan las causas por las que una empresa tan original como su Libro de retratos no se había analizado con tiento; o sea, con vistas no solo a la categoría de sus imágenes, sino a los poemas que las escoltan; enmarcándolo junto a otras mixturas (texto y dibujo) del Renacimiento y el Barroco. 
3 He aquí la laguna que este ensayo de Marta P. Cacho viene a colmar, en tanto que lo considero el trabajo definitivo y sistemático -implacablemente sistemático- sobre la inconclusa obra del sanluqueño. Un ensayo, como luego explicaré, que nace con vocación de permanencia. Lo que equivale a decir que no precisa de la lección de ese capítulo del Arte al que he aludido. Dicho de otro modo: Cacho «acierta con cuidado» y «consigue su intento».

4 Sí quiero detenerme un instante en la noción de «curioso de la pintura» (a fin de cuentas es lo que soy). Me faculta para ello el que Pacheco enderezara su Arte a esta clase de individuos. Por más que el adjetivo «curioso» asumiese entonces una serie de notas algo distintas de las que lo adornan en el desierto actual. De veras "curioso», pues, que el Libro de retratos, donde Pacheco llevó a término una aleación de poemas y estampas, sea también un original retablo de emblemas-panegíricos, icónicos-literarios, nunca antes alumbrado en España. He aquí uno de los motivos para su relativo olvido y falta de edición impresa. "Curioso», también, por dar entrada en nuestro país a un tipo de obra (rara avis) en la que trazo y verso se hermanan, fusionan y retroalimentan. Esto es: su Libro podría gustar tanto a los devotos de su paleta cuanto a los lectores de los cultos ingenios allí celebrados, a los que el mismo Pacheco (equiparando su profesión con la del poeta) dirigía sus versos.

5 Significativo ese nudo entre letra y estampa. Más aún, por ejemplo, si consideramos el reciente éxito de dos monografías de Umberto Eco sobre un corpus de obras capitales de la pintura y la escultura universal. Principalmente. La Storia della Bellezza (2004) y su secuela, la Storia della Bruttezza (2007), según las enfoca Eco, reputado semiótico y novelista superventas, pero que tampoco cruza la frontera del "curioso del arte», resucitan aquella fusión codiciada por Pacheco, entendiendo esta vez la prosa del crítico como uno de los platillos de la balanza. Sus lectores no buscan saber si la Gioconda o Monica Bellucci son dos obras de arte (que lo son); y tampoco el rosario de críticas que han despertado desde Vasari hasta nuestros días. Menos aún les atraen esos volúmenes por los fieles duplicados de Giotto, Cranach o Rafael, fácilmente accesibles en internet; o en bellas láminas, y de cualquier tamaño (sin contar tazas y camisetas), en un sinfín de museos. Lo que nos ha embrujado es cómo un intelectual (Eco), que también es artista, reinterpreta esa cadena de retratos. Tal unión de fuerzas, que en Francisco Pacheco era aún más ambiciosa y radical, en tanto que autor de sus poemas y dibujos, confirman la aparente sinrazón del «fracaso» de la obra del suegro de Velázquez y del triunfo de libros como la Hypnerotomachia Poliphili, de Colonna; o, ya en la modernidad, de la Salomé de Oscar Wilde ilustrada por Beardsley. De la Alice's Wonderland de Carroll, para siempre unida a las criaturas de Tenniel. De las dieciséis láminas a color y más de veinticuatro monocromáticas con las que Clarke enalteció los cuentos de Andersen. De los poemas de Tennyson encendidos por el lápiz de Millais. Del Apolo de Machado. Y antes de ayer, de la trilogía Millenium, de Stieg Larsson, cuyas portadas han recaído en las manos del transgresor Gino Rubert. No digamos ya los rostros -tan mágicos como edulcorados- con los que la compañía Disney condicionó la lectura de las historias de Charles Perrault, el propio Carroll, los hermanos Grimm o Collodi. Incluso cuando se reeditan acompañadas por fotogramas de la casa del ratón Mickey (o de los estudios Pixar).

6 Se me opondrá que el Libro de Pacheco poco o nada tiene que ver con los cuentos, en la medida en que carece de ese ingrediente de narración, de diégesis, que sí poseen cada uno de los «productos» antedichos. Y será verdad. En parte. Está próximo, en cambio, a 
los «verdaderos retratos» de Paolo Giovio, al tratado de Jusepe Martínez (según Karin Hellwig) y -me atrevería a añadir- a los emblemas de Saavedra, a las medallas de Pisanello y al ajuar iconográfico del Macabeo (1638) de Miguel de Silveira, con aquellas veinte magníficas calcografías de Nicolás Perrey, quien también ejecutó los retratos del autor y de los dedicatarios, Ramiro Felípez de Guzmán, Duque de Medina de las Torres y virrey del reino de Nápoles, y su esposa, Anna Caraffa (vid. E. Sánchez García, Imprenta y cultura en la Nápoles virreinal: los signos de la presencia española, Firenze, Alinea, 2007, pp. 12-13). A lo que invita el Libro, pues, es a un diálogo entre poesía y dibujo que exige sincronizar las tornadizas agujas de la Historia (y de la edición) en lo que concierne a la valía y los receptores de «empresas» de este jaez.

7 Nótese que no he evocado siquiera las cifras, muy respetables, que estamos dispuestos a pagar por el catálogo de una exposición puntual de un artista puntual, glosado por unos señores que a menudo nos resultan unos perfectos desconocidos. Bastaría con situarlo en los anaqueles del Prado o de la National Gallery. Concedo, por supuesto, que un catálogo nunca será una obra artística, aun cuando su objeto de estudio sean las piezas de arte.

Este largo excurso apunta varios de los hallazgos del Libro de retratos y la dificultad para clasificarlo -aun con pinceladas comunes- junto a iniciativas más o menos similares desde el Cuatrocientos en adelante. Lo acentúo porque uno de los méritos de Marta Cacho es aclarar la íntima trabazón entre los versos y las imágenes. Su investigación viene a sumarse, en definitiva, a una creciente veta de estudios áureoseculares que atiende al resto de manifestaciones estéticas para hablar de tópicos, lugares o escuelas de poesía, profundizando justo en la escritura inserta o derivada de tales manifestaciones.

9 Si hubiera que trazar un linaje durante la última centuria, pienso que el libro de Cacho hubiera complacido a Giovanni Pozzi, acaso el mayor impulsor de esta línea: La parola dipinta (Adelphi, 1981) y Sull'orlo del visible parlare (Adelphi, 1993). Autoridad a la que sumaría la de Lina Bolzoni -uno de los pocos nombres no listados en su bibliografía-, que nos ha brindado La rete delle immagini (Einaudi, 2002) y Poesia e ritratto nel Rinascimento (Laterza, 2008); la monografía de Antonio Sánchez Jiménez sobre la huella de la pintura en la producción lopesca (El pincel y el Fénix: pintura y literatura en Lope de Vega Carpio, Madrid, Iberoamericana, 2011) y los artículos del número dedicado a la lírica y la pintura que Jesús Ponce ha coordinado para la revista Criticón (2012).

En resumidas cuentas, vivimos una clara floración de los asedios artístico-literarios en el hispanismo, y las aportaciones de Marta P. Cacho Casal (vid. asimismo «Portrait Drawings by Francisco Pacheco and the British Nineteenth-Century Art Market», Master and Drawing, XLVIII, 4, 2010, pp. 447-455) han de ser tenidas muy en cuenta. Por dos virtudes: 1) al terreno de los filólogos ella viene a sumar un rico caudal de saberes que deriva de dos disciplinas tan acordadas como la Historia y la Historia del Arte; y 2) en más de un capítulo hace gala de un método deudor del que Javier Portús ha rentabilizado en obras como Pintura y pensamiento en la España de Lope de Vega, Guipúzcoa, Nerea, 1999.

11 «Pacheco y su fortuna», marbete para el primer bloque, ofrece una síntesis de los juicios iniciales sobre el suegro de Velázquez -no demasiado favorables-. Desde los Diálogos (1633) de Carducho hasta August Mayer y su Die Sevillaner Malerschule (1911). Todo ello con el fin de llegar al Libro de retratos, perdido hasta 1864, y a la revalorización del artista por Jonathan Brown y Bonaventura Bassegoda. Las fases de un 
enjuiciamiento, pues, condicionado por el Parnaso español (1715-1724), de Palomino, y el Diccionario histórico de los más ilustres profesores de las Bellas Artes (1800), de J. A. Ceán Bermúdez. A ellos se anclan, en esencia, investigadores foráneos como Cumberland, Maxwell, Lefort o Justi. No obstante, Marta Cacho añade otros nombres que irradiaron un mejor conocimiento del sanluqueño: José María Asensio, autor de Francisco Pacheco: sus obras artísticas y literarias (1876-1886), y el «grupo de los alemanes», con Justi y el citado Mayer a la cabeza.

12 Carducho evidencia que el Libro de retratos fue más conocido entonces que el Arte de la pintura, publicado póstumamente en 1649. Además, el «Discípulo», uno de los personajes de sus Diálogos, lee el poema De Francisco Pacheco en honra de Bartolomé Carduchi, que se cierra con una elegía por su muerte. Nótese esta circunstancia, pues el proceder del suegro de Velázquez en su Libro será siempre la inclusión de los textos solo cuando el retratado hubiera fallecido. La atención al detalle por parte de Marta Cacho es tan esmerada que aventura que la supresión de ese poema en otra edición de los Diálogos pudo obedecer al deseo de que el Conde Duque de Olivares ofreciera al italiano la decoración de una parte del Salón de Reinos en el Palacio del Buen Retiro, al que Carducho contribuiría con tres pinturas. Y es que aquel poema en el que Pacheco ensalzó al tratadista había salido, a la postre, del magín de un hombre mucho más vinculado a Felipe II (y por ello a la edificación del Escorial) que a Felipe IV.

Palomino nos devuelve la imagen de un Pacheco maestro de Velázquez, entreverada por algunos errores biográficos que Ceán pulió un siglo más tarde. Este último corrigió varios de los fallos del «Vasari español», como el del supuesto viaje a Italia del pintor andaluz. Menos decisivas, sin duda, las contribuciones de Maxwell, Blanc y Lefort, hasta el punto de que solo la monografía de Asensio y Toledo, dos veces matizada y ampliada, supuso un salto cualitativo, en la medida en que fue él quien halló el manuscrito original del Libro. También compraría la única copia moderna, encargada por su antiguo propietario para atraer a posibles bibliófilos. Entre sus pesquisas, de lo más detectivescas, el acierto de considerar inacabado este manuscrito, por una parte, y la intención de identificar el resto de retratos que pudieron haberlo integrado, descollando los de Lope, Velázquez y Jerónimo Carranza.

El lector sonreirá con los denodados empeños de Asensio por relacionar el autorretrato verbal de Cervantes en las Ejemplares (1613) con su tesis de que Pacheco había incluido un retrato del alcalaíno en una de las pinturas que realizó para el convento mercedario de Sevilla (1599-1601).

A Justi debemos el aprecio del estilo literario de Pacheco y un estudio más abarcador del Libro, en función de la teoría del retrato vertida en el Arte de la pintura, que este hispanista supo aplicar a la obra que nos ocupa, muy deudora, según él, de los Elogia (1577) de Giovio y de los dibujos de retratos de Ottavio Leoni (1578-1630). Mayer, por encima de sus diferencias con Justi, ratificó varias de estas premisas, rescatando las cartas del pintor a Valentín Díaz y el concepto de «Escuela sevillana», en la que Pacheco se presentaba como modelo de «latinista» $\mathrm{y}$ «académico».

El estado de la cuestión (1978-2010) también resulta bien cribado. Cacho arranca de los trabajos de Brown, quien arraigó la idea de que Pacheco componía sus textos en equipo, con el apoyo de una comunity of scholars, y traza una línea que nos conduce hasta los de Valdivieso y Serrera, a propósito de la escuela sevillana del primer tercio del siglo XVII; Carrete Parrondo y Bassegoda, de los pocos que se han ocupado del análisis material e histórico del manuscrito, ahondando el segundo en sus modelos, número de estampas y 
la plausible asociación de uno de los dibujos sin rubricar con Diego Hurtado de Mendoza.

17 La verdad es que "gracias al estudio de Manuela Mena sobre el dibujo en Sevilla ha sido posible atenuar la visión crítica y cargada de prejuicios sobre el arte de Pacheco». Aunque Cacho también se detenga en el libro de Fallay d'Este (2001) sobre el Arte de la pintura. Con todo, la primera descripción física del Libro de retratos data de 1997 y fue llevada a cabo por Juan Antonio Yeves. En primer lugar, da noticias de las relaciones de Pacheco con otros poetas y autores (centrado en la amistad entre el suegro de Velázquez y Pedro Espinosa, también poeta y pintor, sugiero la consulta del artículo de Francisco López Estrada, «Documentos sobre Pedro Espinosa (1613). (Fundación de las capellanías de Nuestra Señora de Gracia, en Archidona, y de la Magdalena, en Antequera)", Estudios sobre literatura y arte dedicados al Profesor Emilio Orozco Díaz, Universidad de Granada, 1979, II, pp. 287-295); por otro lado, el Libro tiene repercusión como obra epidíctica, género que se ha resituado lo suyo en jornadas como las organizadas por el FoRell en la Universidad de Poitiers (2010).

Notables son los acercamientos al Libro de Reyes y Piñero, Soria Ortega, Núñez Rivera y Barea, que ha investigado los epitafios latinos que Pacheco reprodujo al pie de algunos de sus elogios. Prueba de la honestidad intelectual de Cacho es el apartado sobre las tareas pendientes: la ausencia de una edición crítica y la necesidad de abundar en los manuscritos que el pintor reunió a lo largo de su vida, especialmente el ms. Span 56 de la Houghton Library de Harvard. Desde el punto de vista iconográfico, hay que «establecer hasta qué punto el estilo de Pacheco fue "italianizante" o se inspiró en estampas holandesas y flamencas».

El segundo capítulo («Perfil biográfico y artístico») vale sobre todo por la necesidad de contextualizar al personaje y, más aún, por las apostillas de Marta Cacho, siempre atinadas, a las palabras heredadas de los maestros. Así, comienza por la infancia y los años de formación junto al casi desconocido Luis Fernández, con el que Pacheco habría comenzado a trabajar a la edad de once o doce años (c. 1575). También repasa su empleo como tasador, su residencia fuera de Sevilla durante 1611, su condición de estofador y de «veedor de pinturas sacras». La trayectoria artística de este vecino de Sevilla se caracterizó, pues, por una serie de aportaciones originales y por su influjo en otros pintores de la época, destacando el techo de la Casa de Pilatos (1600) y el Juicio final (1611).

20 Su relevancia como teórico, el primero en España, llevó a Brown a preguntarse cuántos artistas siguieron sus comentarios sobre la iconografía de la Inmaculada y la representación de Cristo crucificado con cuatro clavos (y una curiosidad me asalta: ¿cuántos poetas se ocuparon de este asunto a raíz de contemplar un cuadro?) Para plantear alguna tesis quizá resulte útil echar un vistazo a un ensayo de Jean Leclercq: L'amour des lettres et le désir de Dieu, París, Les Éditions du Cerf, 1957). ¿Hasta qué punto sonetos como el dedicado A Jesucristo en la Cruz («Desplegar como un velo en los coluros»»), también de Espinosa, deben algo a las ideas de Pacheco? Y recorriendo el mismo camino, pero en el sentido contrario, ¿cuáles fueron las autoridades seguidas por el sanluqueño para definir su lectura iconográfica del Calvario? Hasta donde alcanzan mis saberes, el tema se documenta ya en el beato Juan de Ávila (Tratado del amor de Dios para con los hombre, § 6: La locura de amor). Y la tradición de san Bernardo y el Pseudo-Buenaventura converge en un grupo descriptivo de cinco elementos: la cabeza, los brazos, las manos, el costado y los pies. Para todo ello remito a un artículo 
de R. Ricard: «El tema de Jesús crucificado en la obra de algunos escritores españoles de los siglos XVI y XVII», Estudios de literatura religiosa española, Madrid, Gredos, 1964, pp. 227-245.

21 No obstante, Navarrete ha precisado que el modelo iconográfico de Pacheco tuvo que ser Durero, que instituyó el paradigma con cuatro clavos, al que él y Velázquez se ciñeron sin titubeos. Detalles al margen, Cacho también repara en alrededor de treinta de dibujos, muchos de los cuales conservados en el gabinetto de los Uffizi y procedentes de la colección Santarelli. A este propósito, la estudiosa, cuando analiza un torso que se halla en la Biblioteca Nacional de Madrid (1595), niega, en función del dibujo y de la propia caligrafía, la atribución a Pacheco que se ha venido repitiendo desde Barcía. Merecen algunas páginas tres folios relacionados con el techo que el pintor decoró en Sevilla para el tercer duque de Alcalá y sus dimes y diretes con otros mecenas. Fernando Enríquez de Ribera, el coleccionista de arte hispalense más destacado de la época, quizá fuera el promotor -así se ha escrito- de que en la Casa de Pilatos se reuniera la «famosa academia» de Pacheco, aun cuando Cacho albergue muchas dudas, sobre todo durante las ausencias del duque de la capital andaluza. No en vano, más adelante aporta pruebas concluyentes en contra de la existencia de dicha academia, con la que se ha especulado a partir de la escuela de gramática de Mal Lara. Hay que elogiar de nuevo el rigor de la especialista, que no vacila a la hora de rectificar en este punto a autoridades como Sánchez Escribano o Jonathan Brown. Tampoco se sabe si el duque de Alcalá colaboró en la redacción del Libro. Difícil conocer si fue el mismo noble quien se lo encargó y a quien iba destinado, puesto que ya había apoyado económicamente a miembros de los círculos literarios de Sevilla, como Juan de la Cueva, Jáuregui y Rodrigo Caro.

Otro asunto por dilucidar es la faceta de Pacheco como editor y coleccionista de textos. Bassegoda ha desbrozado bien este punto y la reconstrucción de la biblioteca ideal de Pacheco ya se ha llevado a cabo (parcialmente) por varios especialistas. Valdría la pena cotejar esos datos con los que se desprenden del catálogo de Pedro Ruiz Pérez sobre la de Velázquez (De la pintura y las letras. La biblioteca de Velázquez, Sevilla, Consejería de Cultura de la Junta de Andalucía, 1999). Mientras tanto, dado que no se conserva el inventario de bienes post mortem de Pacheco, Cacho aduce que gracias a la generosidad de Juan Antonio Yeves y Javier Krahe ha tenido noticia de la existencia de un ejemplar de la primera edición italiana del tratado Della simmetria dei corpi humani, libri quattro (Venecia, 1591), de Durero, con firma de Pacheco, aunque sin glosas marginales. Acerca de la predilección del pintor sanluqueño por el genio del Renacimiento teutón, y su fortuna en España, Cacho da cuenta de varias entradas bibliográficas. Podría rendir fruto, asimismo, la consulta del reciente Durero y Cranach. Arte y humanismo en la Alemania, Madrid, Fundación Colección Thyssen-Bornemisza, 2007.

No hay duda de que Pacheco invirtió mucho tiempo trabajando en las bibliotecas. Se conocen tres recopilaciones de manuscritos que le pertenecieron (con mención especial para el Libro de varios tratados de graciosidad y erudición, de diferentes autores, que alberga poemas, tratados y cartas de Quevedo y Alcázar, entre otros) y para las que dibujó una portada. Además hay otros con su firma que son copias de libros ajenos, destacando la controversia sobre las anotaciones de Garcilaso entre Herrera y el Prete Jacopín, los poemas de Francisco de Rioja y una colección de sonetos de Arguijo. Lo que lleva a pensar que mostró cierto desinterés hacia la prosa y el teatro, a los que probablemente otorgó un rango inferior que el concedido a la poesía. 
El capítulo tercero ( «El Libro de retratos: composición del manuscrito e historia del texto») parte de la descripción del testimonio conservado en la Fundación Lázaro Galdiano. Aunque no desfila por este epígrafe ninguna referencia a los principales hitos de la Bibliografía material (Greg, McKerrow, Moll, Lucía Megías, Martín Abad o Garza), hay que señalar que es tan pulcro como riguroso. Lo destacable es que la dispositio y el cuidado del Libro hacen pensar en un texto preparado para la imprenta. Sin embargo, los 56 retratos -Bassegoda los consideró la última voluntad de su autor, que llegó a hablar de 170- no siguen un orden lógico, pues «no reflejan criterios como el cronológico, el estamento social, la profesión o la nacionalidad». Por ejemplo, Felipe II abre el Libro, pero aparece con el número 42, lo que no deja de ser un irónico guiño del destino. Como se sabe, los protagonistas son todos luminarias, la mayoría andaluzas, que vivieron entre los reinados de Felipe II y Felipe IV: eclesiásticos (el grupo más numeroso), escritores, humanistas, soldados, artistas y músicos. ¿Cabría pensar, de nuevo con un horizonte literario por detrás, en la Galleria de Marino, definida como una «enciclopedia de lo visible»?

Con precisión de entomólogo, Cacho se detiene en cada uno de los puntos que conducen a la manufactura del Libro: encuadernación, menciones del mismo en otras fuentes (los Anales de Zúñiga), el paso de mano en mano hasta su compra por Asensio, la historia del manuscrito, del que se ha llegado a aventurar (improbable) que pudo manejarlo Goya, y las leyendas sobre su paradero en 1864. Estas páginas son tan estimulantes que se leen casi como una película de suspense. La autora insiste en la rareza del mismo, en tanto que Pacheco no tenía mecenas, aunque fuera una obra de lujo, y en que nunca se planteó publicarlo (frente a la opinión más corriente). Lo que Marta Cacho puntualiza sin ambages es que el Libro debía de estar previsto como un volumen más amplio de lo que hoy se conserva. Y se adentra en buscar causas para la falta de unidad en la serie dedicada a los frailes mercedarios; o para el trío de poetas sevillanos que forman Herrera, Mal Lara y Mosquera de Figueroa, lo que hace pensar en que la obra fue probablemente reorganizada tras la muerte de Pacheco. Otro cantar es por qué algunos retratos carecen de elogio o de marco, y los que se han perdido, como el de Pedro Sigler y Carranza, amén de la seductora presencia o no de alguna mujer entre los dibujados.

26 A continuación, describe un manuscrito de la Real Biblioteca de Madrid que alberga otro conjunto de estampas (con sus correspondientes elogios) realizadas también por Pacheco y coleccionada por el británico Julian Benjamin Williams. Su parecido con las del Libro de la Fundación Lázaro Galdiano es obvio, aunque la autora incide en su estilo menos cuidado y en el color de las tintas (que del rojo y negro previo se reducen a negro). Los personajes, con frecuencia artesanos y músicos, no son famosos, pero sí sevillanos (Sancho Hernández, Pedro de Mesa, Manuel Rodríguez...). El mérito de Cacho es haber subrayado la cercanía textual entre los elogios de un manuscrito y otro. Lo que habría que ver (acaso no me ha quedado claro) es hasta qué punto se producen trasvases o copias nítidas entre ellos.

No carece de interés, aunque pase de puntillas por esta anécdota, otro retrato (quizá de Francisco de Rojas, Moreto o Cueva) de Pacheco (semejante a los de la colección de Williams) en la Biblioteca Nacional de Madrid, en una hoja suelta y sin encuadernar. Para Cacho nunca formó parte del Libro.

Alrededor de los elogios gira el capítulo cuatro. Tras razonar la inclusión de Felipe II, que nació en Valladolid pero fue concebido en Sevilla, demuestra cómo Pacheco se posicionaba como cantor y dibujante de los méritos del hijo de Carlos V, magnificando 
su papel como mecenas de las artes. Respecto a la cronología, apunta que la portada se remonta hasta 1599, pero los elogios para los retratos de la Real Biblioteca, que son anteriores al Libro, pueden fecharse entre 1582 y 1612. Conclusión: el artista lo empezaría cuando tenía unos veintitrés años y aún seguía retocándolo cinco años antes de su muerte. Prueba evidente de que se trata de un auténtico y ambiciosísimo work in progress. Entre los modelos de los encomios hay que citar a Giovio y las Vite de Vasari; si bien las citas o estímulo para sus poemas casi nunca aparecen indicadas. Cacho ha documentado la deuda con lemas bíblicos y referentes librescos concretos, como los de Baltasar Porreño (Dichos de Felipe II), Cristóbal Mosquera de Figueroa (Prefación a la descripción de la galera) o el licenciado Luis de Muñoz (Vida y virtudes del venerable varón el P. M. Fray Luis de Granada), cuyo rastro desempolva en unas tablas comparativas.

Tampoco renuncia a pronunciarse sobre la supuesta existencia de un libro de Pacheco dedicado a los artistas, para el que habría que considerar una decena de dibujos depositada en la Hispanic Society de Nueva York. Atribuidos a muchos pintores (Pacheco entre ellos), Cacho los ha examinado y concluye que ninguno puede asignársele con certeza al sanluqueño, pues piensa que intervinieron hasta tres artistas distintos. Igualmente sistemático su cotejo entre los elogios de artistas entre el Arte de la Pintura y el Libro, ejemplificado con calas fidedignas en los casos de Céspedes, Luis de Vargas o Pedro de Campaña (Peter de Kempeneer), el único extranjero entre los «varones ilustres» del Libro.

El capítulo quinto («El docto Pacheco: poemas, inscripciones y epitafios») se centra en el centenar de trovas y epigramas que se recogen en la versión actual del Libro. Reflejo del auge del tópico de Ut pictura poesis (sorprende la ausencia en sus notas del muy citado ensayo de Antonio García Berrio y Teresa Hernández, Ut poesis pictura. Poética del arte visual, Madrid, Tecnos, 1988), permiten «establecer paralelismos entre esta obra y las antologías poéticas del Siglo de Oro», como las Flores (1605) de Espinosa, entre cuyas plumas también figuró la de Pacheco. Remito sobre este particular a sendos libros de Belén Molina (La trama del ramillete. Construcción y sentido de las Flores de poetas ilustres de Pedro Espinosa, Sevilla, Fundación Lara, 2003) y Mercedes López Suárez (Tradición petrarquista y manierismo hispánico: de las antologías a Luis Martín de la Plaza, Málaga, Universidad, 2009). Cacho argumenta cómo la composición de poemas en alabanza de pintores era una práctica habitual en la España del XVII, y Pacheco probablemente se postuló como precursor. Las referencias a los dibujos como tales son escasas en dichos textos, pero tienen interés los compuestos por el mismo Pacheco como rúbrica a la firma de sus retratos: pensemos en los que versan sobre tres colegas de gremio: Céspedes, Campaña y Vargas; o en los que dirige al predicador Farfán, buen amigo suyo, como se deriva de ciertos pasajes del Arte. Y no creo que respondiera a una mera razón de simpatía, pues andan muy faltas de estudio las relaciones entre la pintura y los sermones barrocos (temas, géneros y fuentes). Sin ir muy lejos, Ormaza, oculto bajo la máscara de «Pérez de Ledesma», incluía unos capitulillos finales en su Censura de la elocuencia (1648) que tituló precisamente «pinturas».

Otro aspecto importante es la intervención de Pacheco en los versos de otros autores, como los que Juan de Espinosa compuso para el retrato de su tío homónimo, y los modelos para el Libro, objeto del capítulo seis. Además de Paolo Giovio, que le sirve a Cacho para explicar la incidencia de la compleja noción (tal como la entendía Pacheco) de "verdadero retrato», y de Leoni, no es seguro que esta sea una fuente tan directa. Recordemos que las ediciones ilustradas de los Elogia se publicaron solo después de la 
muerte de su autor y el encargado de sacarlas fue Pietro Perna, con la colaboración del grabador Tobias Stimmer. Todo ello nos lleva a la imitatio en la tratadística de Pacheco. En el Arte, según indica Cacho, muestra su desacuerdo con los planteamientos de Armenini en su De' veri precetti della pittura (1586), insistiendo en que el artista debe cumplir dos requisitos: 1) que el retrato sea muy parecido al original; y 2) que esté «bien dibujado y pintado con buena manera de colorido, fuerza y relievo». Premisas que le sirven a la historiadora para establecer la tipología de estampas que hermosean el Libro: 1) retrato «hecho en vida» (la mayoría sacerdotes y frailes, a pesar del pudor y la reticencia de muchos de ellos); 2) retrato «original de colores», inspirados casi siempre (por causa de los fallecimientos) en estampas de otros artistas, como la efigie de Carlos Negrón realizada por Alonso Sánchez Coello o la xilografía de Mal Lara que firmó Juan Bautista Vázquez; 3) retrato «al natural», para describir un autorretrato de Pedro Campaña; y 4) retratos post mortem, como los del mercedario Juan Bernal y Francisco Sarmiento de Mendoza, obispo de Jaén.

La monografía de Cacho, que le ha valido el Premio Internacional Alfonso E. Pérez Sánchez (2010), se cierra con unas conclusiones acerca de la relación entre el Arte y el Libro, compuestos simultáneamente y con un método similar, aunque sus fuentes sean bien distintas, el contenido del Libro sea más biográfico y literario que teórico y, a la postre, Pacheco pensara en dos tipos de público: pintores (Arte) y, diría yo, poetas e historiadores aficionados a la pintura (Libro): "curiosos del arte», como apunté al principio. Muy útil también el Apéndice I («Índice del manuscrito del Libro de retratos en la Fundación Lázaro Galdiano»).

Excepción hecha de alguna minucia bibliográfica (El culto sevillano de Juan de Robles dispone de texto crítico en el haber de Alejandro Gómez, Sevilla, Universidad, 1992), no veo razón para que una edición con las cincuenta y seis láminas (varias han sido reunidas por Cacho en dos cuadernillos internos) del Libro vea la luz más pronto que tarde.

No niego que me hubiese gustado un análisis retórico de los epigramas, pero entiendo que ha dejado esa tarea (como la de la edición) a los filólogos. Pocas dudas tengo de que -si alguna vez se afronta- seguiría restringida a un círculo de bibliófilos, por más que contribuyera, y mucho, a los desvelos de los que nos dedicamos al Barroco. Cierto que es difícil augurarle (cuando se haga) un éxito como los de Eco. Y menos aún como el de los cuentos infantiles ilustrados o las joyas que propone la editorial Libros del Zorro rojo, casi obligada a distribuir por la red. Si hallamos mayor disfrute en leer Las flores del mal con las ilustraciones de Pat Andrea que sin ellas es porque esa «entente» con Baudelaire armoniza en nosotros; de ahí que haya que apostar por ese horizonte de mercados como reducto donde el Libro de retratos podría hallar una tan definitiva como rumbosa publicación. Hasta entonces, la monografía de Cacho es la brújula para navegar por sus páginas. De acuerdo con lo transcrito en el segundo apéndice («Carta de don Juan Infante de Olivares a Pacheco (1 de septiembre de 1631))», ella ha puesto a mejor luz unos textos (y unas estampas) que nos confirman que el verdadero modo de eternizar literaria e históricamente- la biografía de un rey, o de un obispillo andaluz, no puede ser otro que dibujarlos. 


\section{AUTORES}

RAFAEL BONILLA CEREZO

Universidad de Córdoba 